\title{
Liver cirrhosis mortality rates in Britain from 1950 to 2002: an analysis of routine data
}

David A Leon, Jim McCambridge

\section{Summary}

Lancet 2006; 367: 52-56

See Comment page 10

Non-Communicable Disease Epidemiology Unit,

Department of Epidemiology and Population Health, London School of Hygiene and Tropical Medicine, London, UK (Prof D A Leon PhD); and

National Addiction Centre, Institute of Psychiatry, King's College London, London, UK (J McCambridge PhD)

Correspondence to:

Prof David Leon,

Non-Communicable Disease Epidemiology Unit, Department of Epidemiology and Population Health, London School of Hygiene and Tropical Medicine, London WC1E 7HT, UK david.leon@Ishtm.ac.uk

Background Rates of mortality due to cirrhosis of the liver are an important indicator of population levels of alcohol harm. Total recorded alcohol consumption in Britain doubled between 1960 and 2002, giving rise to a need to examine and assess cirrhosis mortality trends.

Methods Mortality rates were calculated for all ages and for specific age-groups (15-44 years and 45-64 years) for cirrhosis of the liver. Rates were directly age-standardised to the European standard population and compared with rates from 12 western European countries for the period 1955-2001.

Findings Cirrhosis mortality rates increased steeply in Britain during the 1990s. Between the periods 1987-1991, and 1997-2001, cirrhosis mortality in men in Scotland more than doubled (104\% increase) and in England and Wales rose by over two-thirds (69\%). Mortality in women increased by almost half (46\% in Scotland and $44 \%$ in England and Wales). These relative increases are the steepest in western Europe, and contrast with the declines apparent in most other countries examined, particularly those of southern Europe. Cirrhosis mortality rates in Scotland are now one of the highest in western Europe, in 2002 being $45 \cdot 2$ per 100000 in men and 19.9 in women.

Interpretation Current alcohol policies in Britain should be assessed by the extent to which they can successfully halt the adverse trends in liver cirrhosis mortality. The situation in Scotland warrants particular attention.

\section{Introduction}

Alcohol consumption is a major public health problem, and the cause of about $4 \%$ of the global burden of disease. This proportion is similar to that of tobacco and hypertension, and has risen to about $7 \%$ and $12 \%$ in western and eastern Europe, respectively. ${ }^{1}$ Rates of alcohol consumption in the general population have been known to be associated with those of liver cirrhosis mortality for almost half a century, ${ }^{2}$ and cirrhosis mortality rates are an important indicator of alcohol harms. ${ }^{3}$ They have been influential in the WHO reviews of options for alcohol policies over three decades. ${ }^{46}$

Total recorded alcohol consumption in Britain doubled between 1960 and 2002. This was the result of several factors: a reduction in the real price of alcohol, an increase in availability of alcohol, and heavy promotion by the alcohol industry. ${ }^{3}$ The Chief Medical Officer for England has previously drawn attention to the cirrhosis mortality rate for England, which roughly trebled between 1970 and 1998, while the European Union rate reduced by about

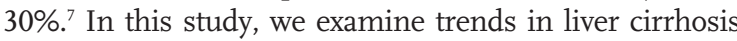
mortality rates in Scotland and in England and Wales up to 2002, and place them in the context of corresponding trends in other western European countries over the past 50 years.

\section{Methods}

Mortality rates were calculated from data in the WHO Mortality Database downloaded from the Geneva website in August, 2005. At the time of writing this constitutes the most detailed consolidated European data on cirrhosis mortality. It contains counts of deaths by cause, single year of death, 5-year age-group, and sex for all countries reporting mortality to WHO from 1950 to 2002, together with the corresponding population denominators. These data were those lodged with the WHO by the corresponding national statistics offices.

Mortality rates were calculated for all ages and specific age-groups (15-44 years and 45-64 years) for cirrhosis of the liver. Rates were directly age-standardised to the European standard population. Over the period 1950-2002, several different revisions of the International Classification of Diseases (ICD) were used. The codes used to define cirrhosis of the liver were: A105 (full code 581) in ICD7; A102 (full code 571) in ICD8; B348 (full code 571) in ICD9; and K70, K73, K74 in ICD10.

Age-standardised mortality rates for Scotland and for England and Wales combined were calculated for 1950-2002, both as annual rates and as 5-year aggregates. These rates were compared with those for 12 other western European countries and with the mean rate for these countries. The countries and years included in this comparison group were dictated by the need to have a complete series for each country included for as long a period of time as possible. 11 countries had yearly mortality data available for every year from 1955 to 2001: Austria, Finland, France, Germany (data for East and West Germany before unification were combined), Ireland, Italy, Netherlands, Norway, Portugal, Spain, and Sweden, but Denmark only had data for 1955-2000. In 2000 , the mid-year population of these 12 countries comprised $73 \%$ of the population of all western European countries (excluding the UK). The mean mortality rate for this comparative group of other European countries was 
calculated as the arithmetic mean of age-standardised rates for every country. This calculation was done in preference to calculating a mean weighted by population size, since we wished to elucidate Britain's position relative to the distribution of rates by country rather than relative to some arbitrary aggregate European population. Average yearly changes in mortality rates in Scotland and in England and Wales over the most recent decade (1997-2001 compared with 1987-91) were estimated from a linear regression of rates against individual year as a continuous variable. Data management and analyses were done in STATA version 8.0.

\section{Results}

Since the early 1950s, there has been a substantial increase in liver cirrhosis mortality rates in Scotland and in England and Wales for both men and women (figure). The steady increase that took place until the end of the 1970 s accelerated in the 1980s, and again from 1990 to 1994 onwards. Between 1950-54 and 2000-02, rates in men increased by a factor of five in England and Wales, and a factor of six in Scotland. In women there were corresponding four-fold increases in rates. The pattern of increase was similar in both the 15-44 years age-group and the 45-64 years age-group, although the absolute rates in the older age-group were much higher.

By sharp contrast, mortality rates for both men and women, and for both age-groups, for the mean of other European countries rose steeply from 1955, reaching a peak in the early 1970s. Subsequently, reductions in mean mortality rates of $25-30 \%$ have been seen in men in both age-groups and in older women, with little consistent change in rates over time in women aged 15-44 years. Across both age-groups and sexes, the mortality rates in Scotland are now about double that of the European comparison group, with the rates in England and Wales rapidly approaching or greater than the European mean.

Trends in the mean of other European countries obscure striking country-specific and regional variations. As can be seen in table 1 there has been a steady long-term decline in mortality rates in France, accompanied by a more recent substantial reduction in the predominantly wine-drinking countries of southern Europe (Italy, Spain, and Portugal) in both men and women. In northern Europe, reductions in rates are apparent in Germany, Austria, and Sweden for both sexes, and in Norwegian men. Increases in mortality rates over both recent and longer term time periods are seen in Finland, Netherlands, and Ireland in both sexes and in Danish men, and increasingly in Danish women. These various changes in rates have resulted in the position of England and Wales relative to other countries moving steadily upwards from having the lowest cirrhosis mortality rates in 1957-62. The relative position of Scottish women and men has also deteriorated. In the latest period for which comparisons were possible (1997-2001), they have the second and third highest rates respectively.

\begin{tabular}{|c|c|c|c|c|c|c|}
\hline & \multicolumn{2}{|c|}{ 1957-1961 } & \multicolumn{2}{|c|}{ 1987-1991 } & \multicolumn{2}{|c|}{$1997-2001$} \\
\hline & Men & Women & Men & Women & Men & Women \\
\hline Austria & $43 \cdot 4$ & $13 \cdot 5$ & 56.6 & $18 \cdot 1$ & $43 \cdot 5$ & 16.7 \\
\hline Denmark & $11 \cdot 7$ & $15 \cdot 6$ & 28.0 & $12 \cdot 9$ & $34 \cdot 2^{*}$ & $15 \cdot 6^{*}$ \\
\hline England and Wales & $3 \cdot 4$ & $2 \cdot 2$ & $8 \cdot 3$ & $5 \cdot 4$ & $14 \cdot 1$ & $7 \cdot 7$ \\
\hline Finland & $9 \cdot 9$ & $5 \cdot 5$ & $23 \cdot 8$ & $8 \cdot 1$ & $28 \cdot 7$ & $9 \cdot 9$ \\
\hline France & $48 \cdot 4$ & $19 \cdot 9$ & 31.9 & $14 \cdot 1$ & 28.1 & $10 \cdot 8$ \\
\hline Germany & $25 \cdot 2$ & $11 \cdot 1$ & $35 \cdot 8$ & $14 \cdot 5$ & $33 \cdot 6$ & 13.9 \\
\hline Ireland & $5 \cdot 4$ & 3.9 & 7.8 & $5 \cdot 3$ & $11 \cdot 1$ & 6.5 \\
\hline Italy & $29 \cdot 6$ & $10 \cdot 2$ & $37 \cdot 4$ & $16 \cdot 2$ & $26 \cdot 5$ & $12 \cdot 2$ \\
\hline Netherlands & $7 \cdot 8$ & $4 \cdot 7$ & $9 \cdot 4$ & $5 \cdot 3$ & $9 \cdot 7$ & 5.9 \\
\hline Norway & $7 \cdot 7$ & 6.6 & $13 \cdot 1$ & $6 \cdot 1$ & $12 \cdot 1$ & $6 \cdot 7$ \\
\hline Portugal & $43 \cdot 3$ & $19 \cdot 0$ & $52 \cdot 4$ & $16 \cdot 9$ & $34 \cdot 7$ & $11 \cdot 1$ \\
\hline Scotland & $8 \cdot 2$ & $6 \cdot 1$ & $16 \cdot 9$ & $11 \cdot 1$ & $34 \cdot 4$ & $16 \cdot 1$ \\
\hline Spain & 28.9 & $14 \cdot 2$ & 34.8 & $11 \cdot 0$ & $25 \cdot 1$ & $8 \cdot 2$ \\
\hline Sweden & $9 \cdot 2$ & $4 \cdot 7$ & $13 \cdot 7$ & $6 \cdot 2$ & $13 \cdot 5$ & $5 \cdot 6$ \\
\hline
\end{tabular}

Rates directly age-standardised to the European standard population. *Rates are 1997-2000 only.

Table 1: Standardised mortality rates for liver cirrhosis at all ages per 100000 per year
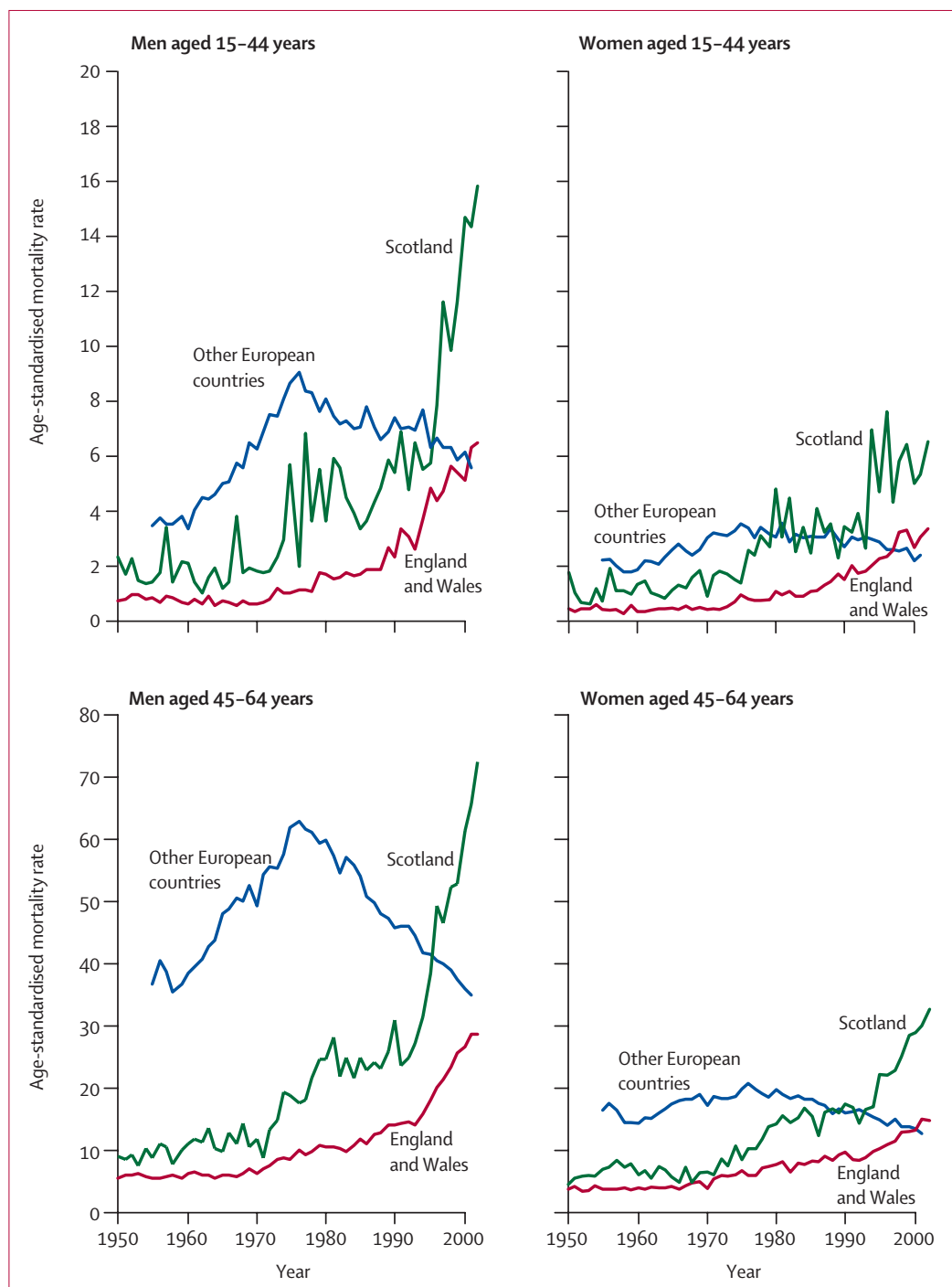

Figure: Time trends in age-standardised mortality rates for liver cirrhosis per 100000 by age-group, sex, and country between 1950 and 2002 


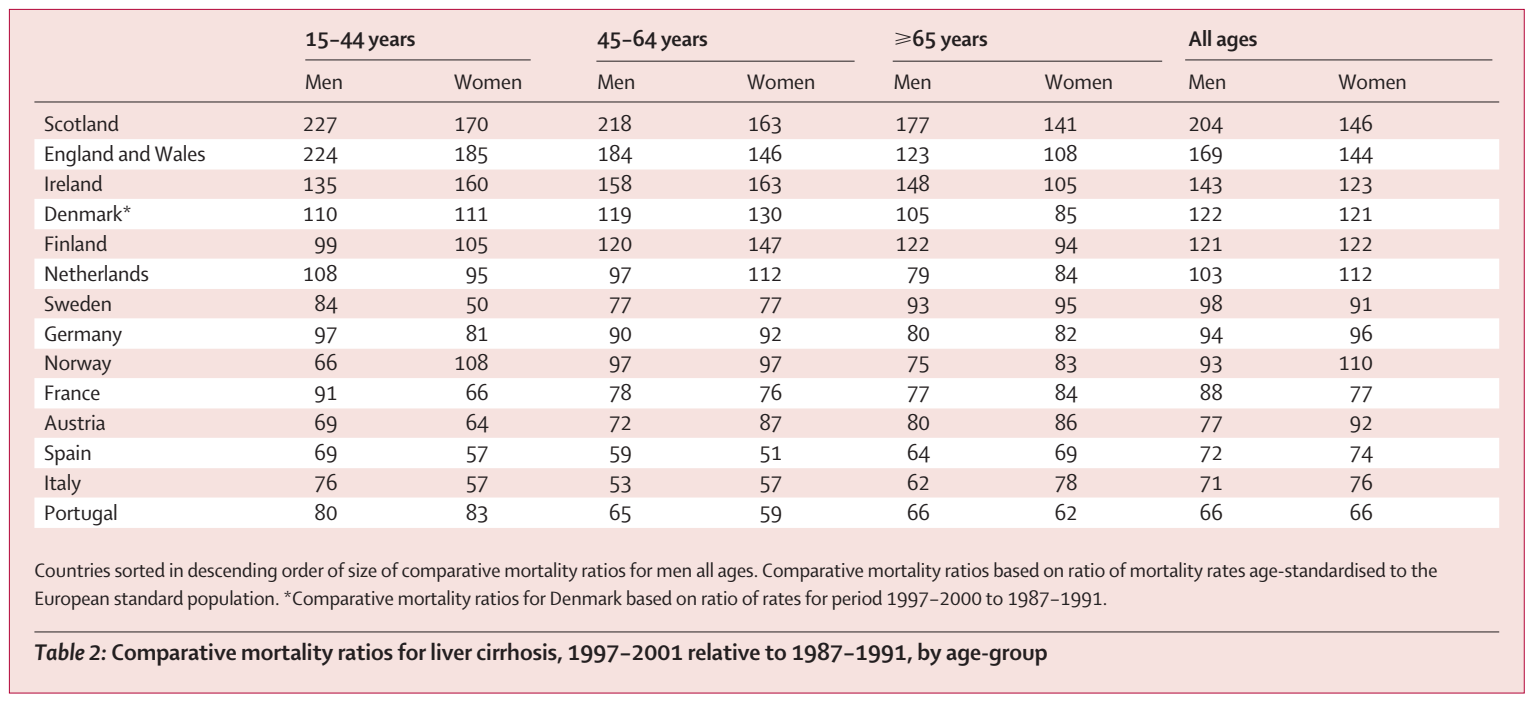

The extent of changes (1997-2001 relative to 1987-91) in mortality rates in specific age-groups and at all ages are shown in table 2 in the form of comparative mortality ratios (100 representing no change). The countries of southern Europe and France have had the largest proportional reductions in death rates due to liver cirrhosis in men and women. By contrast, several northern European countries (including Scotland, England, and Wales) have seen increases.

The rate of increase in mortality rates over the recent decade is highest in Scottish men in all age-groups, and in Scottish women aged 45 years or older. For women aged 15-44 years, the rate of increase for those in England and Wales alone exceeds that in Scotland. Within the 45-64 years age-group, only Irish and Finnish women, and above 65 years only Irish men, have higher rates of increase in cirrhosis mortality than those in England and Wales and in Scotland. At all ages, British men and women have, by some margin, the largest proportional increases in mortality during this time.

Table 3 provides data on the absolute rather than the relative increase in rates over the decade in these same

\begin{tabular}{|c|c|c|c|c|}
\hline & \multicolumn{2}{|l|}{ England and Wales } & \multicolumn{2}{|l|}{ Scotland } \\
\hline & Men & Women & Men & Women \\
\hline \multicolumn{5}{|c|}{ Rate in 2002 per 100000 per year } \\
\hline $15-44$ & $6 \cdot 5$ & $3 \cdot 4$ & $15 \cdot 8$ & $6 \cdot 5$ \\
\hline $45-64$ & 28.9 & $14 \cdot 9$ & $72 \cdot 6$ & $32 \cdot 8$ \\
\hline$\geqslant 65$ & $26 \cdot 7$ & 6.8 & 57.5 & $24 \cdot 9$ \\
\hline All ages & $17 \cdot 5$ & $9 \cdot 4$ & $45 \cdot 2$ & $19 \cdot 9$ \\
\hline \multicolumn{5}{|c|}{ Change in rate per $100000(95 \% \mathrm{Cl})$ per decade for $1993-2002$} \\
\hline $15-44$ & $3 \cdot 5(2 \cdot 3-4 \cdot 8)$ & $1.6(0 \cdot 9-2 \cdot 3)$ & $12 \cdot 1(8 \cdot 9-15 \cdot 3)$ & $1 \cdot 4(2 \cdot 3-5 \cdot 1)$ \\
\hline $45-64$ & $17 \cdot 1(15 \cdot 5-18 \cdot 7)$ & $6 \cdot 8(6 \cdot 0-7 \cdot 7)$ & $47 \cdot 2(39 \cdot 8-54 \cdot 6)$ & $17 \cdot 7(14 \cdot 9-20 \cdot 5)$ \\
\hline$\geqslant 65$ & $7 \cdot 8(4 \cdot 8-10 \cdot 9)$ & $3 \cdot 6(2 \cdot 5-4 \cdot 8)$ & $32 \cdot 0(20 \cdot 7-43 \cdot 2)$ & $8 \cdot 2(3 \cdot 1-13 \cdot 2)$ \\
\hline All ages & $10 \cdot 0(6 \cdot 6-13 \cdot 4)$ & $4 \cdot 4(3 \cdot 2-5 \cdot 7)$ & $29 \cdot 7(24 \cdot 6-34 \cdot 8)$ & $7 \cdot 3(3 \cdot 4-11 \cdot 1)$ \\
\hline
\end{tabular}

Rates directly age-standardised to the European Standard population. Change in rate per decade estimated from a linear regression of rates against individual year as a continuous variable.

Table 3: Liver cirrhosis age-standardised mortality rates per 100000 in England and Wales and in Scotland age-groups and for all ages in Scotland, and in England and Wales. The steepest increase in mortality rates in both England and Wales and in Scotland are seen in the 45-64 years age-group for both sexes.

\section{Discussion}

Over the past quarter of a century, the reduction in cirrhosis mortality rates in western Europe has largely been driven by the decline in overall alcohol consumption in the mainly wine-drinking countries of southern Europe. Increases in cirrhosis mortality rates have been seen across the beer-drinking and spiritdrinking cultures of northern Europe. The British trends thus represent an exaggerated example of these wider northern European trends, resembling most closely the trends in Ireland. In Britain, however, the increases in mortality rates are steeper, are apparent for both men and women, exist across all age-groups, and are accelerating. Although Britain used to have some of the lowest cirrhosis mortality rates in Europe, this advantage has been rapidly eroded. Scotland in particular now has some of the highest rates in western Europe. Although absolute rates in England and Wales remain relatively low, in the most recent years they have risen steeply and are now on a par with or have exceeded the western European average.

There have been several changes in the ICD used to categorise cause of death. There has been particular concern about changes in the definition of alcohol-related deaths as a consequence of the shift from ICD9 to ICD10 in England and Wales. ${ }^{8}$ However, ICD10 was only introduced in England and Wales in 2001 and in Scotland in 2000, ICD9 having previously been in place throughout the UK from 1979. Thus the steep rise in cirrhosis mortality in Britain has been evident throughout this time and cannot be an artifact of change in ICD revisions. With respect to the other European countries mentioned here, the change to ICD9 occurred in 1979 or later (with the 
exception of Denmark, which has never used this revision), whereas the change to ICD10 took place between 1994 and 1999.

This acceleration of the longer-term trend in liver cirrhosis mortality rates across Britain is extremely worrying, and needs to be urgently addressed. This concern is especially true for Scotland, where rates have exceeded those in England and Wales since the early 1930 s, with the differential widening consistently since the early $1950 \mathrm{~s},{ }^{9}$ especially so since the early 1990 s in those in middle age. The most obvious cause of the increase in rates across Britain since the early 1970s is increasing overall alcohol consumption. Per capita alcohol consumption has more than doubled in the UK over the past 40 years. Although beer consumption has been stable, increased consumption of wine and spirits in particular have contributed in a disproportionate way to this trend. ${ }^{3}$ Thus the relative effect of changing overall consumption is difficult to separate from that of changes in the types of alcohol being drunk.

Time series analyses of cirrhosis mortality in 14 European countries from 1950 to 1995 have established that change in overall rates of drinking is accompanied by change in rates of cirrhosis mortality. ${ }^{10}$ The strongest associations between changing rates of consumption and cirrhosis mortality are seen in those northern European countries in which drinking of spirits predominates. ${ }^{10}$

After earlier analyses, ${ }^{11}$ Roizen and colleagues ${ }^{12}$ in the USA, and Kerr and co-workers ${ }^{13}$ in five predominantly beerdrinking English-speaking countries, identified spirits consumption to be largely responsible for the associations between alcohol and mortality rates from cirrhosis of the liver. Some interpretations of these data have regarded these specific associations of spirits as being due to unknown confounders in the absence of a precisely defined biological mechanism. ${ }^{14}$ Kerr and colleagues, however, do not discount the possibility that it is the toxic properties of the spirits themselves that are the causal agents. ${ }^{15}$ It is plausible that greater consumption of more potent forms of alcohol (spirits and wine) enhances the effect on cirrhosis mortality of changing average consumption.

Another possible explanation is increased heavy drinking. ${ }^{16}$ This suggestion is not supported, however, by the available self-reported male consumption data, in which the proportion of men drinking above various risk thresholds has increased only modestly since the late 1980s in Britain. ${ }^{17}$ However, substantial increases in consumption by women, particularly younger women, have been reported over the same period. ${ }^{17}$ Somewhat strangely, the self-reported data reveal no substantial differences between Scotland on the one hand, and England and Wales on the other. However, binge drinking, which is not well captured in available survey data, has previously been proposed to be more common in Scotland.$^{18}$ It is possible that there have been undetected increases in heavy drinking, or increased consumption in those who are already heavy drinkers. The absence of high-quality alcohol consumption data, particularly on a regional and national basis, is a profound handicap to further study.

Although attention has been focused on alcohol, it is important to note that Britain has experienced an epidemic of hepatitis $\mathrm{C}$ in current and former injecting drug users. This increase might account for some of the increase in cirrhosis mortality. ${ }^{19}$ However, there are several respects in which the patterns of hepatitis $\mathrm{C}$ infection do not fit with our findings about cirrhosis mortality. First, prevalent hepatitis $\mathrm{C}$ cases are in general in younger people. For example, $86 \%$ of the 8000 cases diagnosed by Scottish laboratories from 1991 to 1998 were aged between 15 and 44 years, and only $9 \%$ were aged 45-69 years. ${ }^{20}$ By contrast, the proportional increases in cirrhosis mortality over the same period were similar in both age-groups. Second, southern Europe has also experienced an increase in hepatitis $\mathrm{C}$ for similar reasons, but rates of cirrhosis there have been declining. Italy, for example, has about double the prevalence of injecting drug use, and also roughly double the prevalence of hepatitis $\mathrm{C}$ among injecting drug users as Britain. ${ }^{21}$ Unfortunately, further rigorous assessment of the contribution of hepatitis $\mathrm{C}$ to these trends and differences is hampered by the absence of comparable international trend data for incidence and prevalence. ${ }^{22}$

Several other causal factors have been implicated in liver cirrhosis. These include nutritional factors such as obesity, which seems to be associated with increased risk of liver cirrhosis independent of alcohol consumption. ${ }^{23}$ However, differences in obesity are unlikely to provide an explanation for the international differences we noted, since there is no correlation between obesity and liver cirrhosis rates for the countries we have assessed. ${ }^{24}$ For example, Austria and Denmark have notably high rates of cirrhosis mortality for both men and women, but in 2000 had a prevalence of obesity of under $10 \%$ - half that seen in Britain. Moreover, despite the big differences between Scotland on the one hand, and England and Wales on the other as regards to cirrhosis mortality, in 1998 the prevalence of obesity in Scotland in those aged 16-74 years was only slightly higher than in England: 20\% versus 17\% in men, and $22 \%$ versus $21 \%$ in women. ${ }^{25}$ With respect to the temporal trends in cirrhosis, although rates of obesity have increased substantially in Britain over the past few decades, they have also increased in many other European countries, including some of those which now show steep downward trends in cirrhosis mortality such as Spain. ${ }^{26}$ Finally, the role of socioeconomic disadvantage per se needs to be considered. Cirrhosis in Britain has historically been contrasted with that in the US as being a disease of the affluent rather than the poor. ${ }^{11}$ However, socioeconomic disadvantage in itself is unlikely to provide an explanation for the trends and differences we have seen.

What explains what is happening in Scotland? Between 1890 and 1910, the cirrhosis mortality in Scotland was about half that in England and Wales.' The situation 
nowadays is the reverse. Indeed, overall life-expectancy and mortality in Scotland is not improving as much as in most other western European countries, with smoking in particular identified as a major contributor. ${ }^{27}$ Better data and further research on drinking patterns and on other potential determinants of cirrhosis mortality, such as hepatitis $\mathrm{C}$ and obesity, are needed to understand fully the substantial and widening differences in cirrhosis mortality between Scotland and England and Wales.

Although the contribution of obesity and hepatitis $\mathrm{C}$ to national mortality rates due to liver cirrhosis has yet to be clearly shown and quantified, as we have argued above, there is very strong evidence that alcohol is a major driver of population cirrhosis mortality rates in high income countries. In this context, the British Government has decided to eschew specific control of the overall rate of drinking as an instrument of public policy in the first ever strategy for alcohol harm reduction in England, ${ }^{28}$ despite the rapidly increasing cirrhosis mortality rates. The recent comprehensive deregulation of local alcohol controls will further increase alcohol availability, with the likely consequence of increasing consumption. ${ }^{29}$ An early assessment of increased availability in Scotland in the 1970s identified no harmful effect on the basis of broad similarity in trend data from England and Wales. ${ }^{30}$ To us, this finding seems both premature and too narrowly focused.

Almost 40 years ago, a long-term cross-national comparative study concluded that "The methods used in the United Kingdom which have succeeded in reducing mortality from cirrhosis of the liver are, first, progressive increases in taxation of alcoholic beverages in order to decrease their availability to increasing proportions of the population and, second, restriction of the hours of sale of alcoholic beverages." ${ }^{11}$ We seem to be currently unlearning the lessons available to us from history, with what are likely to be predictable consequences. If limiting overall consumption is not an acceptable goal for alcohol policy, perhaps cirrhosis mortality rates are an appropriate key indicator of the extent to which alcohol harms are really reduced.

Contributors

D A Leon led the data analyses on which this paper is based.

J McCambridge led drafting of the text of the report.

\section{Conflict of interest statement}

We declare that we have no conflict of interest. The sponsor had no role in study design, data collection, data analysis, data interpretation, or the writing of the report. The corresponding author had full access to all the data in the study and had final responsibility for the decision to submit for publication.

\section{Acknowledgments}

J McCambridge is supported by a Wellcome Trust Health Services Research Fellowship. We are grateful to the anonymous reviewers for helpful comments.

\section{References}

1 Room R, Babor T, Rehm J. Alcohol and public health. Lancet 2005; 365: 519-30.

2 Seeley JR. Death by liver cirrhosis and the price of beverage alcohol. Can Med Assoc J 1960; 83: 1361-66.

3 Academy of Medical Sciences. Calling time: the nation's drinking as a major health issue. London: Academy of Medical Sciences, 2004.
Bruun K, Edwards G, Lumio M, et al. Alcohol control policies in public health perspective. Helsinki: Finnish Foundation for Alcohol Studies, 1975.

5 Edwards G, Anderson P, Babor TF, et al. Alcohol policy and the public good. Oxford: Oxford Medical Publications, 1994.

6 Babor T, Caetano R, Casswell S, et al. Alcohol: no ordinary commodity. Oxford: Oxford Medical Publications, 2003.

7 Donaldson L. On the state of the public health: the annual report of the Chief Medical Officer of the Department of Health 2001. London: Department of Health, 2001.

8 Baker A, Rooney C. Recent trends in alcohol-related mortality, and the impact of ICD-10 on the monitoring of these deaths in England and Wales. Health Stat Q 2003; 17: 5-14.

9 Duffy JC, Latcham RW. Liver cirrhosis mortality in England and Wales compared to Scotland: an age-period-cohort analysis 1941-81. J R Stat Soc 1986; 149: 45-59.

10 Ramstedt M. Per capita alcohol consumption and liver cirrhosis mortality in 14 European countries. Addiction 2001; 96: S19-35.

11 Terris M. Epidemiology of cirrhosis of the liver: national mortality data. Am J Public Health 1967; 57: 2076-88.

12 Roizen R, Kerr WC, Fillmore KM. Cirrhosis mortality and per capita consumption of distilled spirits, United States, 1949-1993. BMJ 1999; 319: 666-70.

13 Kerr WC, Fillmore KM, Marvy P. Beverage-specific alcohol consumption and cirrhosis mortality in a group of English-speaking beer-drinking countries. Addiction 2000; 95: 339-46.

14 Gruenwald PJ. The epiphenomena of beverage-specific effects. Addiction 2000; 95: 347-56.

15 Kerr WC, Fillmore KM, Marvy P. New hypotheses and methodological challenges: a reply to the commentaries. Addiction 2000; 95: 355-58.

16 Norstrom $\mathrm{T}$. The abolition of the Swedish alcohol rationing system: effects on consumption distribution and cirrhosis mortality. $\mathrm{Br}$ J Addict 1987; 82: 633-41.

17 Walker A, Maher J, Coulthard M, Goddard E, Thomas M. Living in Britain: Results from the 2000/01 General Household Survey. London: Stationery Office, 2001.

18 Wilson P. Drinking habits in the United Kingdom. Popul Trends 1980 Winter 14-18. London, HMSO.

19 Henry JA, Moloney C, Rivas C, Goldin RD. Increase in alcohol related deaths-is hepatitis C a factor? J Clin Path 2002; 55: 704-07.

20 Office for Public Health in Scotland. Scottish needs assessment programme: hepatitis C. Glasgow: Office for Public Health in Scotland. 2000. http://www.show.scot.nhs.uk/scieh/infectious/ hepatitisc/Documents/Additional\%20publications/hepatitis\%20C\%2 0SNAP\%20report\%202000.pdf (accessed Aug 26, 2005).

21 European Monitoring Centre for Drugs and Drug Addiction. The state of the drugs problem in the European Union and Norway: annual report 2004. Luxembourg: Office for Official Publications of the European Communities, 2004

22 Desenclos JC. The challenge of hepatitis C surveillance in Europe. Euro Surveill 2003; 8: 99-100.

23 Ioannou GN, Weiss NS, Kowdley KV, Dominitz JA. Is obesity a risk factor for cirrhosis-related death or hospitalization? A populationbased cohort study. Gastroenterology 2003; 125: 1053-59.

24 Organisation for Economic Cooperation and Development. OECD health data 2005: statistics and indicators for 30 countries. Paris: OECD Publishing, 2005.

25 Shaw A, McMunn A, Field J, eds. The Scottish Health Survey 1998 volume 1. Edinburgh: Scottish Executive, 2000.

26 Gutierrez-Fisac JL, Banegas Banegas JR, Artalejo FR, Regidor E. Increasing prevalence of overweight and obesity among Spanish adults, 1987-1997. Int J Obes Relat Metab Disord 2000; 24: 1677-82.

27 Leon D, Morton S, Cannegieter S, McKee M. Understanding the health of Scotland's population in an international context. Glasgow: Public Health Institute of Scotland, 2003. http://www.phis.org.uk/ projects/network.asp?p=FF (accessed June 15, 2005).

28 Cabinet Office. Alcohol harm reduction strategy for England. London: Cabinet Office, 2004.

29 Room R. Disabling the public interest: alcohol strategies and policies for England. Addiction 2004; 99: 1083-89.

30 Duffy JC, Plant MA. Scotlands's liquor licensing changes: an assessment. BMJ 1986; 292: 36-39. 